\title{
O CONHECIMENTO CIENTÍFICO E A MULTIMODALIDADE INFORMACIONAL
}

\section{CONOCIMIENTO CIENTÍFICO Y EL MULTIMODALIDAD INFORMATIVO}

\author{
Luiz Carlos Flôres Assumpção* \\ André Porto Ancona Lopez**
}

\begin{abstract}
RESUMO
Introdução: No contexto científico, a informação só poderá ser considerada objetivo científico se forem dentro de normas e regras preestabelecidas, ou seja, com as informações registradas - teorias e resultados de pesquisas - 0 que pode ser colocado à prova, sendo refutada ou não.
\end{abstract}

Objetivo: Analisar a informação multimodal no contexto do conhecimento científico com a teoria dos três mundos de Popper.

Metodologia: $\mathrm{E}$ o ponto de partida é uma pesquisa bibliográfica. No primeiro momento, a definição do que é informação e informação como coisa. No segundo momento, vamos nos ater ao contexto da informação multimodal, passando o terceiro momento nas teorias de três mundos de Popper e em particular o terceiro mundo ou mundo 3.

Resultado: No terceiro momento as considerações em defesa da informação gravada para fazer parte da estrutura do contexto científico onde a informação é considerada como algo multimodal física e tangível para ser do mundo 1 , e do mundo 3 de Popper.

Conclusão: Nesta análise pudemos inferir que a informação multimodal faz parte do contexto científico e é estruturada como uma coisa fazendo parte do terceiro mundo de Popper

Palavras-chave: Informação. Informação como coisa. Conhecimento. Ciência. Multimodalidade.

\footnotetext{
* Doutorando do Programa de Pós-graduação em Ciência da Informação da Faculdade de Ciência da Informação da Universidade de Brasília (UNB). Bolsista CAPES. E-mail: Icfasms@gmail.com

** Doutor em História Social pela Universidade de São Paulo (USP). Professor do Programa de Pós-graduação em Ciência da Informação da Faculdade de Ciência da Informação da Universidade de Brasília (UNB) E-mail: apalopez@gmail.com
}

Inf. Inf., Londrina, v. 21, n. 1, p. $04-28$, jan./abr. 2016.

http:www.uel.br/revistas/informacao/ 


\section{INTRODUÇÃO}

Hoje somos apresentados a todos tipos de informação, via jornais, a mídia televisiva, rádio, internet, textos, livros, imagens, filmes, etc. porém não temos certeza de se tratar de uma informação segura. No entanto, há um tipo de informação que é tida como segura, pois está estruturada dentro do conhecimento científico, através da publicação dos resultados das pesquisas desenvolvidas em todos os campos do conhecimento sujeito a refutação ou não. O objetivo deste estudo, é o de analisar a informação multimodal no contexto do conhecimento científico conforme a teoria dos três mundos de Popper. E o ponto de partida, é uma busca bibliográfica para dar o entendimento do que é a informação, a informação multimodal no contexto da ciência sob o aspecto dos três mundos de Popper para termos um embasamento de tais temas.

O escopo deste estudo está sendo delimitado no contexto da ciência como conhecimento objetivo na visão de Popper (1999) situado no que ela chama de terceiro mundo. Neste sentido, buscaremos demonstrar que a tese do mundo 3 ou terceiro mundo de Popper está no contexto da informação registrada, sendo um texto, um artigo, um livro, um filme, uma imagem - uma coisa - e da informação multimodal. Ainda, as relações entre os três mundos e a interação da ciência neste contexto em que ele chama de conhecimento objetivo onde defendemos a informação registrada, tratar-se da informação como coisa, conforme Buckland (1991) e é onde está inserida a informação multimodal.

\section{INFORMAÇÃO}

O que é Informação? De acordo com Buckland (1991, p. 351), "a ambiguidade da informação" enfrenta dificuldades desde que a informação imediata relaciona-se com o "tornar-se informado", com a redução da ignorância e da incerteza. Para o autor, o termo "informação" é em si mesmo é ambíguo e usado de diferentes formas. Pode-se 
perceber que a palavra informação é um tanto complexa em sua descrição. Na concepção de Robredo, "a 'informação' pode ser: registrada, duplicada, transmitida, armazenada, organizada, processada e recuperada" (ROBREDO, 2007, p. 22).

O célebre autor (2007, p. 22) complementa ainda que,

[...] a representação da informação ocorre quando extraída da mente e codificada, pela linguagem natural (falada ou escrita), seguindo normas e padrões (gramática, sintaxe) próprios de cada língua, ou de outras linguagens criadas pelo homem (linguagens de programação, que também têm suas gramáticas e sintaxes). A interpretação da informação de fato gera, um processo de transformação do conhecimento (dentro da mente) em "informação" fora da mente. Então, "informação" seria o conhecimento "externalizado", mediante algum tipo de codificação. Observe-se que isso somente se aplica ao conhecimento já existente na mente. (ROBREDO, 2007, p. 22).

Buckland (1991, p. 351-352) nos traz três significados de "informação": "Informação como processo", "informação como conhecimento" e "informação como coisa", afirmando também que o uso atributivo de "informação" serve para designar as coisas consideradas informativas. A natureza e as características de "informação como coisa" são discutidas, utilizando uma abordagem indireta ("Que coisas são informativas?") ainda se refere que "há uma variedade de 'informação como coisa', que inclui dados, textos, documentos, objetos e eventos". Ademais, refere o autor "[...] seja qual for o armazenamento da informação e sistemas de recuperação, o ato de armazenar e recuperar é necessariamente 'informação-chave'” (BUCKLAND, 1991, p. 353). Neste estudo, abordar-se-á a informação como coisa (grifo nosso), que se baseia em dados (informação registrada) os quais são utilizados pelos cientistas na forma de informação multimodal onde possa ser prova da captação de dados para corroborar nos resultados de suas pesquisas.

Assim, a informação não é uma entidade física, não é um objeto tangível, visível, audível (o que se toca, se vê ou se ouve é o documento 
escrito, gravado, etc. - mundo 1 -, contendo conhecimento registrado, em geral, mediante um código de representação - informação multimodal). Está-se referindo à informação, não considerada um objeto tangível; trata-se da interpretação do que está exposto num texto documento escrito, em uma música, em uma imagem (ROBREDO, 2007, p. 23) - a interpretação está no mundo 3. Nessa acepção a informação é o que o indivíduo interpreta dos dados (ou da coisa em si) um bem intangível está no mundo 2, dos pensamentos, deduções e ou inferências.

Desta forma, as bases iniciais para o desenvolvimento de qualquer pesquisa, em todas as áreas do conhecimento, estão apoiadas nas informações construídas através da representação dos dados, símbolos e ou caracteres pois, o que o cientista faz é justamente a coleta e uso dos dados transformando-os em informação registrada sendo uma coisa multimodal -, gerando conhecimento sobre as mais variadas áreas do saber científico.

De acordo com Marconi e Lakatos (2004, p. 35), o conhecimento científico é comunicável à medida que:

a) Sua linguagem deve poder informar a todos os seres humanos que tenham sidos instruídos pra entendê-la - a maneira de expressar-se deve ser principalmente, informativa e não expressiva ou imperativa: seu propósito é informar e não seduzir ou impor;

b) Deve ser formulado de tal forma que outros investigadores possam verificar seus dados $e$ hipótese - em razão direta da quantidade de investigadores independentes que tomam conhecimento das hipóteses e técnicas, multiplicamse as possibilidades de confirmação ou refutação das mesmas;

c) Dever ser considerado como prioridade de toda humanidade - pois a divulgação do conhecimento é mola propulsora do progresso da Ciência.

Tais assertivas em relação aos dados nos mostram o quanto se faz uso dos mesmos na composição da informação, esta podendo ser escrita, gravada, etc., e que estamos definindo como coisa - de acordo 
com Buckland (1991) - no campo das ciências, isso impõem uma discussão acerca do uso da informação e da multimodalidade informacional para o cientista nas ciências e na formação do conhecimento objetivo científico definido por Popper (1999, 2004, 2006a, 2006b, 2009).

\subsection{Informação Multimodal}

A palavra informação em si mesma traz uma série de definições, no contexto da ciência da informação, vai variar de que forma se decide atuar com a pesquisa em si. Advogamos o caso da informação como coisa - o conteúdo de um livro, um texto, revista, um jornal, um filme, dados em um sistema de banco de dados -, conforme definição de Buckland (1991) e, essa coisa sendo objetiva, física e tangível, armazenada e recuperada de acordo com Robredo (2007), tendo ainda uma permanência em um determinado espaço que é o mundo 3 de Popper.

Assim, vamos apresentar uma definição de Multimodalidade de acordo com Ribeiro (2011, p. 41): "[...]. Multimodalidade é um termo que vem sendo utilizado em estudo que dizem respeito à expressão dos sentidos por meio de diferentes linguagens, especialmente na relação entre texto verbal e a imagem [...]". Ainda, retara sobre os trabalhos de outros autores nesta linha de pesquisa. Contudo, temos um complemento que deve ser levando em consideração quando Ribeiro (2011, p. 41) afirma que "[...] os relatos tratam da leitura ou da produção textual sob uma ótica "nova", a multimodalidade esteve sempre presente na expressão de todo tipo de informação com que lidamos hoje e ontem (e, provavelmente, lidaremos amanhã)". Podemos inferir diante do exposto, onde somos apresentados a todo tipo informação que chegam até nós via, livro, jornal, radio, televisão, internet, etc., e estão numa estrutura informacional multimodal de acordo com Duque (2011).

Em nosso foco, a informação científica, não difere dos demais tipos de informação. Pois, contém todas as características da multimodalidade inclusa na sua estrutura e apresentação. Em um 
trabalho sobre multimodalidade e conhecimento científico em apresentações de Dynkowska e Lobin (2011) demonstram que em todas as apresentações científicas vamos ter a multimodalidade informacional presente. De acordo com os autores, "percebe-se como pano de fundo, uma nova abordagem linguística independente para as apresentações científicas, as do tipo de texto complexo, multimodal". Ainda, complementam: "[...], devido à combinação de diferentes elementos e formas de comunicativas, as apresentações científicas podem ser descritas como multimodal". (DYNKOWSKA; LOBIN, 2011, p.155). Nas comunicações científicas temos o texto em si, o uso de gráficos, tabela, imagens, etc., em demonstração dos resultados encontrados. E, para isso os autores informam: "pode-se atribuir três modalidades para os vários modos de comunicação onde são combinados e sincronizados na fase e execução de uma apresentação: a linguística (na concepção da língua falada), o visual e a modalidade performativa". Em seguida apresentam uma descrição de cada uma dessas três modalidades. De forma simplificada: linguística se refere ao discurso elaborado na fala do apresentador. Visual, ou uso de projeções com textos, gráficos, imagens, etc., performativa que é expressa pela linguagem corporal do apresentador isso nas apresentações dos trabalhos científicos (apresentação de Monografias, Dissertações, Teses e em Seminários Científicos). No entanto, ainda temos no meio acadêmico o conhecimento científico disseminado via publicação de artigos e de revistas específicas da área em que a pesquisa foi desenvolvida. Da mesma forma, encontramos eco em Mueller (2007, p. 128), "[...] a publicação, como pode ser visto, é essencial ao processo da geração e certificação do conhecimento científico [...]". A autora complementa: "[...] a comunicação se dá de duas formas: a informal e formal [...]". Na primeira forma se dá quando um resultado de uma pesquisa circula entre conversas pessoais face a face, aulas etc. No segundo, quando lidos por seus pares e publicado. De acordo com Mueller (2007, p. 130) "[...] a crença da comunidade científica na absoluta necessidade da "avaliação previa" pelos pares é provavelmente o fator mais importante e 
determinante do status científico de um conhecimento [...]". Nesta etapa, compreende-se a leitura por outros pesquisadores da mesma área do conhecimento. Ou seja, outros autores no mesmo programa e/ou comunidade científica conforme definição de Kuhn (2002, 2009). Ao ser publicado, poderá passar pelo crivo da validação, refutação ou falseabilidade conforme Popper (2009). Isso é confirmado por Mueller (2007, p. 131) "[...] depois de publicado, o artigo ou conteúdos do livro estarão permanentemente sujeitos a avaliações e contestações, expostos à crítica de comunidades mais amplas, contemporâneas e posteriores ao autor do livro [...]". A escrita, a linguagem e as formas de estruturação dos artigos, livros etc., passam por um processo de produção do conhecimento científico sob regras, de acordo com Mueller (2007, p. 134) "[...] um dos modelos mais conhecidos foi o proposto por Garvey e Griffith em 1972, onde mostra a sequência de documentos produzidos no fluxo da informação científica desde o início de uma pesquisa [...]". Ainda, [...], "os modelos mostram também como as publicações secundárias e terciárias se seguem à publicação do artigo".

De acordo exposto acima, há confirmação da qual advogamos, a informação registrada - informação como coisa dentro de uma estrutura multimodal - estão no mundo 3 de Popper e fazem parte do suporte para estruturação do conhecimento científico. Então, passaremos à teoria dos três mundos e o entendimento de como ocorrem os tipos de conhecimento do tipo senso comum (popular) e objetivo (científico).

\section{OS TRÊS MUNDOS DE POPPER}

A tese dos três mundos de Popper é defendida em suas obras Em um mundo melhor e em O Conhecimento Objetivo (grifo nosso) -, na primeira obra o autor tenta nos demonstrar os três mundos em interação e para compreensão das coisas dentro de uma lógica abordada nas suas conferências, este estudo trata da lógica matemática. Porém, nessa lógica ele estabelece a segunda obra com o conhecimento e as relações causais com os três mundos. Para o 
entendimento do que estamos expondo, vamos nos ater à tese dos três mundos:

O mundo consiste de, pelo menos, três submundos ontologicamente distintos; ou, com eu diria, há três mundos: o primeiro é o mundo material, ou o mundo dos estados materiais; o segundo é o mundo mental, ou o mundo dos estados mentais; e o terceiro é o mundo dos inteligíveis, ou das ideias no sentido objetivo; é o mundo de objetos de pensamentos possíveis: o mundo das teorias em si mesmas e das relações lógicas, dos argumentos em si mesmos, e das situações de problemas em si mesmas. (POPPER, 1999, p. 152).

Buscamos apresentar a tese dos três mundos de formal geral. No entanto, Popper (1999) descreveu a primeira de forma direta em dar ao mundo físico o nome de "mundo 1", ao mundo de nossas experiências conscientes o de "mundo 2"; e ao mundo dos conteúdos lógicos de livros, bibliotecas, memórias de computador e simulares de "mundo 3" (POPPER, 1999, p.78). Na segunda descrição, o autor nos apresenta um nível de detalhamento mais apurado.

O primeiro, o mundo de objetos físicos ou de estados materiais; segundo, o mundo de estados de consciências ou de estados mentais, ou talvez de disposições comportamentais de agir; e terceiro, o mundo de conteúdos objetivos de pensamento, especialmente de pensamentos científicos e poéticos e de obras de arte (POPPER, 1999, p. 108).

Nestas descrições o mundo 1 e o 2 estão idênticos a sua primeira colocação sobre os três mundos, porém o mundo 3 está de uma forma mais ampla nas suas três descrições. Sendo este mundo 3 um dos pontos de base advogado neste trabalho. Assim, de acordo com as teses dos três mundos, podemos entender o mundo 1 onde temos as coisas materiais físicas, como um móvel, a água, a terra, a natureza. Ou seja, o mundo das coisas físicas e materiais tangíveis que nos cercam. No mundo 2, o autor está se referindo o que o ser humano observa e interpreta do mundo 1 , são os objetos e coisas que são percebidas 
pelos sentidos, pela percepção no qual o ser humano faz sua interpretação via pensamento, deduções e inferências do mundo físico. Sendo, o que ele percebe, pensa, interpreta e decide mentalmente de como vai atuar no mundo físico. Já no mundo 3 é o que ele define de conteúdo, ou seja, a informação registrada - uma coisa multimodal -, entendível por um ser humano como informação podendo fazer uso dela, sendo um texto, um livro, uma revista em meio eletrônico ou impresso, fazendo parte de uma biblioteca. No entanto, o autor esclarece mesmo o livro, o texto, - a informação registrada - etc., fazendo parte do mundo físico - mundo 1, nada é sem um leitor. Só se torna um livro se for realmente entendido; sem isso, é apenas um papel com sinais pretos (POPPER, 1999, p.116). Para o autor,

[...] um livro contém conhecimento objetivo, verdadeiro ou falso, útil ou inútil; e se alguém chegar a lê-lo e aprender com seu conteúdo. [...]. É sua possibilidade ou potencialidade de ser entendido, seu caráter disposicional de ser entendido ou compreendido, ou desentendido ou mal interpretado, o que faz de uma coisa um livro. E esta potencialidade ou disposição pode existir sem jamais haver sido efetivada ou realizada (POPPER, 1999, p. 116).

Assim, a informação estando registrada em um meio físico, sendo uma coisa, ela está no mundo 1. Ela só fará sentido se for interpretada e entendida, isso somente poderá ser feito por um ser humano que conheça e domine a linguagem da qual a obra está registrada - através da leitura, do raciocínio, do pensamento e do entendimento mental que faz parte do mundo 2. No entanto, se o ser humano não conhecer a linguagem e não fizer uso da informação registrada, ela continua no mundo 1. Dessa forma, o mundo 3 é o conteúdo desse registro, que permanece no livro, texto, etc. De acordo com Popper (2006b, p. 20) "o mundo 3 , o mundo dos produto do espírito humano, contém coias tais como livros, sinfonias, esculturas, sapatos, aviões, computadores [...], todos produtos planejados ou deliberados da atividade espiritual humana sejam classificados de mundo 3". Essa explicação, dos três 
mundos nos dá um suporte para o que estamos defendendo no sentido de que a informação como coisa e a multimodalidade informacional está contida no conteúdo que é o mundo 3 e é o livro, o texto etc., fazendo parte do mundo 1 em estado físico. Sendo um bem tangível, onde contém a representação da informação registrada, ou seja, o conteúdo que irá ser interpretado e entendido - bem intangível. Porém, o conhecimento subjetivo, será o que está no cérebro sendo o entendimento do conteúdo interpretado pelo ser humano fazendo parte do mundo 2.

Popper (1999, p. 78) retrata várias teses do mundo 3. No entanto a principal é:

Quase todo nosso conhecimento subjetivo (mundo 2) depende do mundo 3 , isto é, de teorias formuladas linguisticamente (pelo menos virtualmente). Exemplo: nossa "autoconsciência imediata", ou o "conhecimento de si mesmo", que é muito importante, depende muito amplamente de teorias do mundo 3: de nossas teorias a respeito do nosso corpo e da sua existência continuada quando dormimos ou ficamos inconscientes; de nossas teorias a respeito do tempo (sua linearidade); de nossas teorias a respeito de nossa lembrança de experiências passadas com vários graus de nossas expectativas de acordar depois de dormir. Proponho a tese de que a plena consciência de si mesmo depende de todas essas teorias (mundo 3 ) e de os animais capazes de sentimentos, sensações, memória e, portanto, de consciência, não possuem a plena consciência do próprio ser, que é um dos resultados do mundo 3 , especificamente humano.

No mundo 3, é onde especificamente se concentra o conhecimento científico, a informação registrada nos artigos, livros, etc. Porém, para Popper (1999), este mundo está repleto de habitantes presentes no desenvolvimento da ciência - teoria, problemas, hipóteses, etc. Para o autor, "[...] exemplos de conhecimento objetivo são as teorias publicadas em revistas e livros e conservadas em bibliotecas; discussões dessas teorias; dificuldades ou problemas apontados em conexão com essas teorias" (POPPER, 1999, p. 78). E, são habitantes do mundo 3 . 
Popper (1999, p. 109), nos apresenta uma descrição dos habitantes do mundo 3 onde ele diz:

\begin{abstract}
Entre os habitantes de meu "terceiro mundo" há mais especificamente, sistemas teóricos; mas habitantes de igual modo importantes são problemas e situações de problema. $\mathrm{E}$ argumentarei que os moradores mais importantes desse mundo são argumentos críticos e que pode ser chamado - em analogia com um estado material ou um estado de consciência - o estado de uma discussão ou o estado de um argumento crítico; e, naturalmente, os conteúdos de revistas, livros e bibliotecas.
\end{abstract}

Podemos inferir, que a informação registrada - teorias - em livros, artigos eletrônicos, revistas impressas, trata-se da informação como coisa e informação multimodal, onde se aplica o uso da linguagem, de um ou mais tipos de signos para poder compor a estrutura da informação. Desta forma, temos o uso da escrita com elaboração dos textos, a imagem podendo ser uma pintura, uma fotografia, ou exposição de gráficos na tentativa de estruturar a informação de forma compreensível ao entendimento do ser humano. O uso da escrita poderá ocorrer em qualquer idioma, o do escritor ou do leitor. Ou seja, há a necessidade de que um dos elementos que vai compor a informação tenha no mínimo de atribuir a utilização de um tipo de linguagem, porém nada impede de utilizar várias modalidades. A linguagem da informação registrada terá de ser conhecida para ser compreendida - o conteúdo que se refere ao mundo 3. A informação poderá ser composta de texto na tentativa de se explicar, a parte argumentativa - defendida por Popper (1999, p. 121): “[...] as mais importantes criações humanas, como os mais importantes efeitos de retrocarga sobre nós mesmos e especialmente sobre nossos cérebros, são as funções da linguagem humana; mais especialmente, a função descritiva e a função argumentativa".

Ao abordar a linguagem Popper (1999), busca retratar duas funções básicas inferiores que é a auto-expressa e a sinalização (grifo nosso). Também indica o fato de tanto o ser humano quanto um animal 
terem fenômenos linguísticos e essas duas funções inferiores, porém somente o ser humano é consciente dela. Ainda esclarece: "[...] há as posições superiores, e quando elas aparecem as inferiores também estão presentes e que "sempre é possível" explicar qualquer fenômeno linguístico, em termos das funções inferiores, como "expressão" ou uma “comunicação"” (POPPER, 1999, p. 121). E passa a descrever o processo dessas duas funções superiores da linguagem:

Com a função descritiva da linguagem humana, emerge a ideia reguladora da verdade, isto é, de uma descrição que se ajusta aos fatos. [...]. A função argumentativa da linguagem humana pressupõe a função descritiva: os argumentos, fundamentalmente, são acerca de descrições; criticam descrições do ponto de vista das ideias reguladoras de verdade, de conteúdo e verossimilitude (POPPER, 1999, p. 121).

Do exposto, Popper (1999, p. 121-122) traz mais duas observações no qual diz: "Agora, dois pontos aqui é de toda importância":

- Sem o desenvolvimento da linguagem descritiva exossomática - uma linguagem que, como uma ferramenta, se desenvolve fora do corpo - nenhum objeto pode haver para nossa discussão crítica. Mas, como o desenvolvimento de uma linguagem descritiva (e mais, de uma linguagem escrita) pode emergir um terceiro mundo linguístico; e é só deste modo, e só neste terceiro mundo, que se podem desenvolver os problemas e os padrões da crítica racional.

- A este desenvolvimento das funções superiores da linguagem é que devemos nossa humanidade, nossa razão. Pois, nossos poderes de raciocinar nada mais são que poderes de argumentação crítica.

O autor defende a evolução da função argumentativa da linguagem, onde "[...] o mundo autônomo das funções superiores da linguagem torna-se o mundo da ciência [...]" (POPPER, 1999, p. 122):

O significado de "conhecimento", como o de todas as palavras, não tenha a importância, é importante 
distinguir entre diversos sentidos da palavra.

(1) Conhecimento subjetivo, que consiste de certas disposições inatas para agir e das suas modificações adquiridas.

(2) Conhecimento objetivo, por exemplo o conhecimento científico, que consiste de teorias conjecturais, problemas abertos, situações de problemas, e argumentos.

O segundo ponto é o que advogamos, trata-se do conhecimento estruturado em experiências coordenadas e estruturadas sob normas na qual define como ciência. Para tal, ele complementa que "[...] todo trabalho em ciência é trabalho dirigido para o crescimento do conhecimento objetivo. Somos trabalhadores que estamos aumentando o crescimento do conhecimento objetivo tal como pedreiros trabalham numa catedral" (POPPER, 1999, p. 122). O desenvolvimento da ciência perpassa pela discussão do conhecimento do senso comum e do conhecimento objetivo, sendo estruturado pela informação como coisa e a multimodalidade.

\subsection{O Conhecimento: Senso Comum}

De acordo com Popper (1999, p. 77), "a teoria do senso comum do conhecimento, e com ela todos os filósofos até pelo menos Bolzano e Frege, admitiu como certo, erroneamente, que só havia uma espécie de conhecimento - o conhecimento possuído por algum sujeito conhecedor". O autor ainda afirma que: "a esse tipo de conhecimento chamarei de conhecimento subjetivo" apesar do fato de que simplesmente não existe conhecimento subjetivo puro, ou genuíno, ou não adulterado" (POPPER, 1999, p. 77).

Podemos perceber nas colocações de Popper (1999), é que ele está colocando como conhecimento subjetivo, é o conhecimento de senso comum como a crença, o mito e a religião estando na mente do ser humano. Pois, continua afirmando: "a teoria de conhecimento subjetivo é muito antiga; mas torna-se explícita com Descartes:" conhecer" é uma atividade e pressupões a existência de um sujeito 
conhecedor"'. É o subjetivo que conhece". (POPPER, 1999, p. 77). Aqui, observa-se que o autor está tratando do fato do conhecimento passar pela mente humana - mundo 2 - definido como conhecimento subjetivo.

De acordo com Popper (2009, p. 7), "o conhecimento humano tem sido encarado como um tipo especialmente seguro de crença humana, e o conhecimento científico como um tipo especialmente seguro de conhecimento humano". para o autor, conhecimento seguro refere-se ao fato de o conhecimento científico ser registrado, validado e não ter sido refutado. À distinção entre senso comum e o conhecimento científico, são complementadas por Chalmers (1993, p. 139-140) "[...]. Os indivíduos têm duas maneiras de formar conhecimento sobre o mundo: pensando e observando. $O$ pensamento liga-se à teoria do conhecimento racionalista clássica, e a observação à teoria empirista". Essas colocações estão em consonância com Popper (1999, p. 16) em que "[...] qualquer tentativa para chegar a leis científicas gerais partindo de observações particulares é ilusória". De acordo com autor "[...] o Senso Comum, é sempre nosso ponto de partida, mas deve ser verificado" [...]. Ele "tem fornecido o alicerce sobre o qual se erigem até mesmo as mais recentes teorias filosóficas" (POPPER, 1999, p. 66). Explica que "é uma teoria comum e simples":

Se você ou eu quisermos conhecer alguma coisa ainda não conhecida a respeito do mundo, temos de abrir os olhos e olhar ao redor. E temos de aguçar nossos ouvidos e ouvir os ruídos, especialmente feitos por outras pessoas. Assim nossos vários sentidos são nossas fontes de conhecimento - as fontes ou os acessos para nossas mentes (POPPER, 1999, p.66).

$\mathrm{Na}$ crítica à teoria de senso comum do conhecimento Popper (1999, p. 71) apresenta sete pontos de discordância e alega que ela está radicalmente errada em todos os pontos. O conhecimento do senso comum é baseado na observação de um ou mais indivíduos e aceito como verdade subjetiva, sem uma análise crítica e sem o registro da informação com os requisitos das ciências. Como não há aceitação 
como verdade objetiva, não pode ser refutável. Esta é uma forma de conhecimento bastante questionada em termos de ciência. Desta forma, "o conhecimento é tratado como algo exterior, antes que interior, às mentes ou cérebros dos indivíduos" (CHALMERS, 1993, p. 140). O conhecimento do senso comum não tem uma aceitação no campo da ciência por não tratar a formação do conhecimento de forma estruturada, com normas e métodos/metodologias, técnicas e instrumentos - registro e sistematização dos dados para geração da informação ou teoria - nos quais poderia se aproximar da verdade objetiva, a que os cientistas estão em busca.

\subsection{Conhecimento: Objetivo - Científico}

Para Popper (2009), a ciência é uma construção racional exatamente por ser histórica, onde "[...]. Sua construção se dá com base no enfrentamento, pelo homem, de problemas que lhe surgem ao longo da vida, sendo, portanto, irrecusável sua estreita vinculação com a realidade externa e com os fenômenos culturais de cada época" (SCHMIDT; SANTOS, 2007, p. 7). Contudo, Popper (2009, p. 31) afirma que "[...] o trabalho do cientista consiste em elaborar teorias e pô-las à prova". Aqui, podemos entender que pôr a prova trata-se da estruturação da informação como coisa e multimodal, o conteúdo que está no mundo 3 -, onde a informação é registrada e publicada. Onde, "[...] a linguagem, a formulação de problemas, a emersão de novas situações de problemas, teorias concorrentes, crítica mútua por meio de argumentação, tudo isso são os meios indispensáveis ao crescimento científico [...]" (POPPER, 1999, p. 123). Observa-se na afirmação do autor o uso da linguagem se refere ao contexto da informação registrada, onde ele ainda afirma que "[...] só dentro de uma linguagem assim enriquecida é que a argumentação crítica e o conhecimento no sentido objetivo se tornam possíveis [...], como todas as representações linguísticas, são sistemas de signos ou símbolos [...]"(POPPER, 1999, p. 123), o que nos leva a inferir ser justamente o uso da informação 
registrada o conteúdo do mundo 3 - sendo uma coisa - livro, pintura, um registro escrito, etc. -, e podemos dizer que essa coisa poderá estar estruturada com informação multimodal.

De acordo com Popper (2009, p. 61-62), as teorias são fontes de denominação, definidas em métodos e conceitos: "[...] o conhecimento humano consiste em teorias, hipóteses e conjecturas que nós formulamos como produto de nossas atividades intelectuais [...]". O pensador concebe a ciência como uma sucessão de pensamentos, frutos da imaginação criadora do homem - aqui, situada no mundo 2 -, que historicamente se aproxima cada vez mais da verdade (ao mesmo tempo em que, em certo grau, transforma essa mesma verdade) ao transformar o mundo que nos cerca, ou seja, no mundo 3 - utilização da informação registrada sendo entendida e interpretada aceitada ou refutada por um ser humano para atuar ou intervir na realidade. Tal imaginação parece afastar a verdade para uma fronteira cada dia mais distante, sempre capaz de uma explicação cada vez mais abrangente dos fenômenos observáveis, movida sempre pela crítica de nossos erros e pela refutação sucessiva das teorias; uma após a outra, as refutações colocarão novos problemas a serem enfrentados e novas perguntas a serem respondidas. Contudo, de acordo com a visão de Popper (2009) em a lógica da pesquisa científica, o progresso científico demonstrou consistir não em acumulação de observações, mas em superação de teorias menos satisfatórias e sua substituição por teorias melhores, ou seja, por teorias de maior conteúdo. Neste sentido, quando as informações são registradas, serão passíveis de falseamento ou de refutação. Desta forma, após a consulta das teorias existentes, estas registradas com informações multimodais podem ser entendidas no mundo 1, - o físico - por estarem em um meio de registro com possibilidade de recuperação através da leitura e/ou transformadas no mundo 2, dos pensamentos e deduções. Em seguida podendo ser reutilizadas, testadas para falsear e ou serem refutadas. Isso vai ocorrer no mundo 3 , onde, o conteúdo vai ser registrado, e ao ser novamente publicado num outro artigo em meio eletrônico, livro, em revista 
impressa e ou fazendo parte de um acervo na biblioteca. Neste sentido, a objetividade dos enunciados científicos reside na condição de eles poderem ser submetidos a teste e, além do mais, dependem da forma como as informações foram registradas, de como serão reinterpretadas para a execução de um novo teste, sendo, a interpretação e a reutilização da informação. A informação registrada poderá ser usada e interpretada por qualquer um alheio à área de estudos na qual a pesquisa foi desenvolvida, porém não se pode garantir que tal uso e interpretação sejam similares àquela original. Os resultados de um estudo poderão ser ou não aceitos se forem conjecturados, refutados ou falseados pelos seus pares, mediante publicação a qual dará acesso às informações.

De acordo com Popper (2009), o processo de construção de uma nova teoria (ou sistema científico) se inicia com a comparação lógica entre as conclusões obtidas pela teoria construída - buscando uma coerência interna do sistema - com o registro das informações obtidas no decorrer da pesquisa com uso de signos e símbolos, que é quando o registro se vale da interpretação dos dados, transformando-os em informações advogadas neste trabalho. Já que se trata de informação registrada em suporte físico para interpretação, ela pode ser entendida como uma coisa (grifo nosso) conforme Buckland (1991).

O segundo momento é a prova da investigação lógica da teoria para verificar se ela apresenta o caráter de uma teoria empírica ou científica. Posteriormente, segue-se o confronto com outras teorias, a fim de determinar até que ponto a nova teoria construída representa um avanço na ordem científica. Finalmente, há a comprovação da teoria por meio de aplicações empíricas das conclusões que dela se possam deduzir.

Quando Popper se refere a uma teoria construída, subentende-se revisão da literatura - conteúdo registrado nos livros, mundo 3 -, que procura identificar quem ou quais cientistas desenvolvem estudos similares. Entende-se que a verificação empírica englobaria uma discussão sobre a formalidade e pertinência dos métodos científicos 
utilizados para definir se, realmente, a nova teoria estaria ou não alicerçada em definições e técnicas capazes de solucionarem o problema original.

$\mathrm{O}$ autor se refere a métodos/metodologias e teoria aceitas pela comunidade científica - informações registradas podendo ser em forma de artigos publicados em revistas eletrônicas e/ou em papel via revistas impressas sendo a informação registrada e multimodal -, que no entanto, poderão ser verificadas e então serem refutadas ou falseadas conforme propõe Popper, para quem "[...] a tarefa da lógica da pesquisa científica ou da lógica do conhecimento é [...] proporcionar uma análise lógica desse procedimento, ou seja, analisar o método das ciências empíricas" (POPPER, 2009, p. 27). Contudo, Sieczkwoski (2012, p. 41) afirma que "[...] a relação entre os três mundos é causal [...]", onde há uma intersecção lógica entre os mundos de Popper:

Há pontos de intersecção entre o M3 e o M2, do M1 e o M2. Portanto, o M1 e o M3 não se relacionam de forma causal. O M1 e o M3 se relacionam indiretamente, isto é, com a mediação do M2. Aqui há uma lição fundamental na leitura de Popper: o sujeito conhecedor tem uma importância decisiva no interacionismo pluralista. A materialização das teorias do M3 em possibilidades tecnológicas do $\mathrm{M} 1$, passa pela descoberta do sujeito do M2.

Essa relação lógica é estabelecida pelo o que o homem produz dos entendimento descrito no meio físico - Mundo 1 - para o raciocínio, crítica elou aceitação - Mundo 2 - com as conclusões mentais, e em posterior reutilização, uma nova descrição do entendimento e conclusões em um artigo, livro, etc. aparato tecnológico um bem físico Mundo 3. Já no caso do não relacionamento de $M 1$ e $M 3$, é o fato de uma informação registrada não gerar outra informação sozinha. Terá de passar por tratamento pelo homem ou um sistema computadorizado. Dai, poderá ser aceita elou refutada.

De acordo com Schmidt e Santos (2007, p. 12), essa lógica implica, em nossa opinião, que, a partir do estabelecimento dos critérios 
de refutação, uma teoria pode ser falseada ou corroborada. Se ela for falseada, certamente será de modo concludente, caso contrário, novas situações colocarão seus conteúdos à prova novamente. "O falseamento é, sem dúvida, uma contenda entre a teoria e a observação" e a contestação dos dados, considerados como coisa (BUCKLAND, 1991), interpretados e transformados em informações multimodais registradas. Tais registros revelam-se como teoria do que se sucedeu ao resultado do estudo, ou a experiência do que foi o conhecimento científico estruturados numa coisa com informações multimodais em um artigo, teses e dissertações, num livro, num relatório de pesquisa, numa publicação em revista, etc.

Percebe-se que a ciência está em transformação constante e o cientista faz parte do contexto com a produção de informações e conhecimentos registrados - novas teorias - que poderão ou não superar as existentes, mas desde que sejam contestadas e colocadas à prova com rigor lógico e científico. Isso ocorrerá por meio da recuperação da informação como "coisa" (grifo nosso), na forma de textos, artigos, dissertações ou bancos de dados com descrição de resultados - informação multimodal -, que irá gerar novos conhecimentos. Observa-se uma convergência em todas as ciências, em que a informação possa ser transmitida, seja oralmente e/ou por escrito em eventos científicos, por meio de publicações especializadas, sempre fazendo uso da informação como coisa. A informação como coisa pode ser um texto, um livro, etc. se comportando no mundo 1 , o físico e no mundo 3 com o registro do conteúdo. Isso significa que ao tornar público um determinado resultado, este poderá passar pela análise dos pares, sujeito a ser refutado ou conjecturado - mundo 2 (POPPER, 2009), esse processo não compromete a evolução da ciência em si e nem a maturação do cientista. A partir do momento em que o cientista desenvolve o conhecimento objetivo, ele trabalha com os rigores e as normas da ciência, registra seus resultados de pesquisa e os torna públicos, disponibilizando informação registrada - uma coisa com informação multimodal -. Desse processo surgem novos 
conhecimentos e novas teorias que são sempre, em alguma medida, embasadas nas predecessoras, também defendidos por Kuhn (2009). registro dela em um suporte torna a informação como coisa, já que ela passa a ser tangível, aberta à reinterpretação e reutilização na geração de um novo conhecimento, uma nova coisa.

Contudo, de acordo com Bursztyn, Drummond e Nascimento (2010, p. 9-12),

[...]. O meio de comunicação acadêmica por excelência é o texto escrito. [...] $\mathrm{Na}$ vida científica e acadêmica, oralidade rima com perecibilidade. São os escritos que podem aspirar a algum grau de permanência ou, mais ambiciosamente, durabilidade e impacto, dependendo do seu embasamento e da sua qualidade textual. [...] Deve-se lembrar que, quando um pesquisador ou cientista publica um artigo em uma revista científica, ele está "dialogando" com seus pares, que formam uma comunidade.

A precedência da publicação, do registro escrito - informação multimodal -, corrobora a ideia de informação científica como coisa, passível de registro para uso posterior, armazenamento e recuperação conforme definido por Buckland (1991). Ou seja, o conhecimento científico passa por elaborações organizadas com elaboração e/ou formulação de problemas, hipóteses, testes das hipóteses, das observações conjuntas com as teorias e depois de testadas vão para os relatórios de pesquisa, daí vai para outro ciclo que é de validação junto aos pares mais próximos e finalmente publicadas a fim de serem refutadas ou não por especialistas. Essa lógica é expressa por Keneller (1980, p. 98-100) ao fazer uma demonstração de como as investigações científicas são feitas e colocadas ao conhecimento de outros cientistas.

\section{CONSIDERAÇÕES FINAIS}

Buscamos demonstrar o fato de a informação ao ser trabalhada no contexto científico está exatamente no ponto de vista defendido por Buckland (1991) de informação como coisa, ainda, os textos científicos 
são estruturados com a informação multimodal onde se utilizam a escrita no texto, símbolos, gráficos, imagens, etc., em uma determinada linguagem que terá de ser entendida por um outro espectador - um ser humano. Desta forma inferimos que a ciência só poderá ser elaborada por um ser humano com uso de normas e métodos/metodologias sistematizadas na qual possa ser replicada para verificação tendo a aceitação ou refutação dos resultados.

Popper trata da visão e do trabalho do cientista isolado que faz os seus testes e submete-os à apreciação de seus pares - através da informação registrada, tida como coisa e multimodal. O cientista solitário poderá amargar a refutação de seus resultados de pesquisa, sustentada na crítica e na falseabilidade de seu trabalho, realizadas pela interpretação das informações registradas em suporte físico com a informação multimodal - uma coisa. Essa dinâmica, para Popper, é responsável pelo avanço da ciência com a solução de problemas e geração de novas teorias. No entanto, o conhecimento do senso comum não tem uma validade objetiva, ou seja, não passa pelas normas e regras do conhecimento objetivo - científico, com o registro da informação onde possa ser conjecturado, falseado dentro do contexto da lógica da verificabilidade das ciências. Assim, o conhecimento do senso comum está presente no seio da sociedade e é tido como dito popular.

A princípio o conhecimento objetivo - científico, não pode ser feito por empiristas ou racionalistas sozinhos, mas sim por uma combinação de elementos que abrange as origens históricas das teorias. Ou seja, o uso da informação multimodal registrada (armazenamento, recuperação de uma coisa) e envolve os objetivos e valores humanos. Dados os devidos limites de uma generalização, dos autores, em maior ou menor escala, parecem concordar neste sentido. O conhecimento científico é construído de modo coletivo através da informação como coisa e multimodal ao ser estruturado com normas e regras que estão no mundo 3, ao fazer interpretação e uso da informação multimodal registrada livros, textos, etc. publicados em meios eletrônicos ou impressos fazendo parte de um acervo numa biblioteca estando no mundo 1 , bens 
físicos -, quando utilizados e interpretados estão atuando no mundo 2, por ser necessário o ser humano consultar as teorias predecessoras da mesma área do conhecimento e de outras.

Deste modo, os resultados das soluções dos problemas propostos nas pesquisas têm a informação interpretada, depois disponibilizada/publicada - para seu registro com uso de escrita, figuras, etc., da informação está no mundo 3, o conteúdo das teorias -, em outro momento ainda posterior, novamente interpretada, desta feita por outro ser humano, que, por sua vez, irá agregar novos conhecimentos mundo 2 sendo a reinterpretação da informação e suas multimodalidades. O novo conhecimento se diferenciará do original por conter informações e valores oriundos da experiência e da formação desse outro indivíduo.

Ao reinterpretar a informação - saindo do mundo 2 - quando dela se faz novo registro (escritos e documentados com informação multimodal) o cientista irá explicitar a composição contextualizada do novo conhecimento - estruturação do mundo 3 , o conteúdo -, ao trazer à tona suas conclusões. Estas, por sua vez, através de relatórios, publicação de artigos e/ou de livros, tornar-se-ão outro registro entrando no mundo 1, o documento físico -, que servirá também para posterior acesso e recuperação de informação por parte da comunidade científica e/ou para o público em geral sendo o conteúdo científico registrado com multimodalidade informacional estando no mundo 3.

Desta forma, podermos dizer que as teorias científicas ao serem documentadas passarão a ser informações registradas - uma coisa multimodal - de acordo com Chalmers (1993) são um tipo especial de produto social, embora a extensão em que são capazes de lidar com o mundo físico não seja um produto social, não seja determinada socialmente, pois boa parte do trabalho de cientista, mesmo feito de forma coletiva por pesquisar o conhecimento de outros autores, é feito de forma individual. Podemos considerar o conhecimento e a ciência como produtos construídos pelo ser humano. E, este conhecimento somente poderá ser interpretado por outro ser humano que conheça a 
linguagem na qual foi estruturado na tentativa de se conhecer os mistérios da natureza e dos fenômenos sociais a fim de compreendêlos, com melhores informações através das informações multimodais registradas como coisas - um texto, uma imagem, um filme, etc.

\section{REFERÊNCIAS}

BUCKLAND, Michael K. Information as thing. Journal of the American Society for Information Science (JASIS), New York, v. 45, n. 5, p. 351 360, 1991.

BURSZTYN, MARCEL; DRUMMOND, JOSÉ AUGUSTO; NASCIMENTO, ELIMAR P. Como escrever (e publicar) um trabalho científico: dicas para pesquisadores e jovens cientistas. Rio de Janeiro: Garamond, 2010.

CHALMERS, ALAN F. O que é ciência afinal? Brasília: Brasiliense, 1993.

DYNKOWSKA, Malgorzata; LOBIN, Henning. Multimodalidade e conhecimento em apresentações científicas. In: DUQUE, C. Gottschalg (Org.). Ciência da Informação estudos e práticas. Brasília: Centro Editorial, 2011.

DUQUE, C. Gottschalg. (Org.). Ciência da Informação estudos e práticas. Brasília: Centro Editorial, 2011.

KNELLER, George F. A ciência como atividade humana. Trad. Antônio José de Souza. Rio de Janeiro: Zahar, São Paulo: Ed. da Universidade de São Paulo, 1980.

KUHN, Thomas S. A revolução coperniana. Lisboa: Edições 70, 2002.

A estrutura das revoluções científicas. 9. ed. São Paulo: Perspectiva, 2009.

MARCONI, Marina de Andrade; LAKATOS, Eva Maria. Metodologia científica. 4. ed. São Paulo: Atlas, 2004.

MUELLER, Suzana P. M. Literatura científica, comunicação científica. In: TOUTAIN, Lidia Brandão B. (Org.). Para Entender a Ciência da Informação. Salvador: EDUFBA, 2007.

POPPER, Karl Raimund. Conhecimento objetivo. Belo Horizonte: Itatiaia, 1999. 
Brasileiro, 2004.

Lógica das ciências sociais. 3. ed. Rio de Janeiro: Tempo

Conjecturas e refutações. Coimbra: Almedina, 2006a.

Em Busca de um Mundo Melhor. Trad. Milton Camargo Mota.

São Paulo: Martins, 2006b.

2009.

A lógica da pesquisa científica. 14. ed. São Paulo: Cultrix,

RIBEIRO, Ana Elisa. Percepções de adultos e crianças (ainda) analfabetos sobre multimodalidade e discurso visual em jornais impressos. In DUQUE, C. Gottschalg. (Org.). Ciência da Informação estudos práticos. Brasília: Centro Editorial, 2011.

ROBREDO, Jaime. Filosofia da ciência da informação ou ciência da informação e filosofia? - Uma questão que merece ser pensada. 2007. In: CINFORM, 7., 2007, Salvador, UFBA. Disponível em:<http://www.cinform.ufba.br/7cinform/soac/papers/ 369a2be3343ea1ed160564371174.pdf>. Acesso em: 10 set. 2010.

SCHMIDT, Paulo; SANTOS, José Luiz dos. O pensamento epistemológico de Karl Popper. ConTexto, Porto Alegre, v. 7, n. 11, 1 sem. 2007.

SIECZKOWSKI, João Batista C. O pluralismo da tese do mundo 3 de Popper. In: OLIVEIRA, Paulo Eduardo de (Org.). Ensaios sobre o pensamento de Karl Popper. Curitiba: Círculo de Estudos

Bandeirantes, 2012.

TOUTAIN, Lidia Brandão B. (Org.). Para entender a Ciência da Informação. Salvador: EDUFBA, 2007.

\section{Title}

Scientific knowledge and informational the multimodality

\section{Abstract}

Introduction: In the scientific context, information can only be considered objective and scientific if they are within per-established norms and rules, ie the information recorded - theories and research results - which can be put to test, and refuted or not.

Objective: To analyze the multimodal information in the context of scientific knowledge with the theory of the three worlds of Popper.

Methodology: And the starting point is a literature search. At first, the definition of what is and information like thing. In the second phase, we will stick to the context of multimodal information, passing the third time in three worlds theory 
of Popper and in particular the third world or world 3.

Result: In the third phase the considerations in defense of information recorded to be part of the structure of the scientific context where information is regarded as something multimodal physical and tangible to be the world's first and the world 3 Popper.

Conclusion: In this analysis we can infer that the multimodal information is part of the scientific context and is structured as a thing part of the third world of Popper.

Keywords: Information. Information as thing. Knowledge. Science. Multimodality.

\section{Titulo}

Conocimiento científico y el multimodalidad informativo

\section{Resumen}

Introducción: En el contexto científico, la información sólo puede considerarse objetiva y científica si están dentro de las normas y reglas preestablecidas, es decir, la información registrada - teorías y resultados de la investigación - que se puede poner a prueba, y refutó o no.

Objetivo: Analizar la información multimodal en el contexto del conocimiento científico con la teoría de los tres mundos de Popper.

Metodología: Y el punto de partida es una búsqueda de la literatura. Al principio, la definición de lo que es y la información como cosa. En la segunda fase, nos atendremos al contexto de información multimodal, pasando la tercera vez en tres mundos teoría de Popper y, en particular, el tercer mundo o el mundo 3.

Resultado: En la tercera fase de las consideraciones en defensa de la información registrada para ser parte de la estructura del contexto científico, donde se considera la información como algo multimodal física y tangible a ser ante el mundo 1 el mundo 3 de Popper.

Conclusión: En este análisis se puede inferir que la información multimodal es parte del contexto científico y se estructura como una parte algo del tercer mundo de Popper.

Palabras clave: La información. La información como cosa. Conocimiento. Ciencia. Multimodalidad.

Recebido em: 02.12.2013

Aceito em: 01.10.2015 